Mauro Dorato

\title{
Some Contemporary Reflections on Bergson's Time and Free Will
}

\section{Abstract}

By relying on a quotation by F.L. Pogson ${ }^{1}$ to be found in the introduction to his translation of Bergson's Time and Free Will essay, in this paper I discuss Bergson's theory of the relation between time and free will by analysing three key notion of his philosophy, namely that of creative power of nature, of memory and of duration. In particular, I discuss a possible reinterpretation of his metaphysics by using the growing block model of reality, and his anti-associationist philosophy of mind-by him identified with determinism-which seems to require a finite duration of the present experience. Finally, I propose a reinterpretation of his conception of free action by using Kane's contemporary approach to the problem. ${ }^{2}$

\section{Some Methodological Considerations}

There is little doubt that Bergson's philosophical work has always focused on the nature of time, in particular on the difference between the time of our direct experience and the time of physics. ${ }^{3}$ Consequently, Bergson's critique of physical time-regarded by him as a mere spatializing abstraction from the real duration-was not only caused by the philosophical and scientific challenge emerging from Einstein's two theories of Relativity, but predated their famous meeting on April 6, 1922. ${ }^{4}$ Some contemporary reflections on Time and Free Will will show

1 In this paper I will follow Pogson's 1913 translation of the original text, as it has been checked by Bergson himself (Bergson 2001).

2 I thank two anonymous refereed for their important suggestions and Alessandra Campo for her decisive and patient editing help. This paper has benefitted of the grant progetti di ricerca di rilevante interesse nazionale financed by the Italian Ministry of Public Education-Bando 2017 Prot. 2017ZNWW7F.

3 An informative and accessible survey of different views on the nature of time in the $20^{\text {th }}$ century is in Fano and Tassani (2002).

4 Of course, Canales to whom we owe the complete and fascinating reconstruction of their meeting is well aware of this fact. See Canales (2015).

Ә OpenAccess. (C) 2022 Mauro Dorato, published by De Gruyter. (cc) BY This work is licensed under the Creative Commons Attribution 4.0 International License. https://doi.org/10.1515/9783110753707-007 
in what sense Bergson's earlier criticism of physical time affected his later confrontation with Relativity. 'Contemporary' as it is used here implies a conceptual evaluation of Bergson's arguments that is independent of a philological attention to the literature in psychology and neurophysiology that Bergson had read before the completion of his work in 1899. In the following, I will therefore first briefly expose his conception of the creative power of nature and of duration, and then compare his notion of the relationship between time and free will with some relevant contemporary scientific and philosophical theories.

\section{Various Approaches to the Problem of Free Will and Bergson's Position}

Schematizing, in the history of western philosophy we find three different ways of articulating the inextricable conceptual link between time and free will:

(1). Aristotle's logical discussion in the ninth book of De Interpretatione of the so-called "future contingents" (non-necessary future-tense statements) -was based on the thesis that if we attribute a definite truth value to such statements and at the same time accept bivalence, we are not free. If it is now true that tomorrow there will a sea battle, the captain is not free to decide whether he wants to attack or not, since he cannot but attack. The same conclusion holds if it is now false that tomorrow there will a sea battle. And since in virtue of bivalence, a statement is either true or false, in both cases we are not free.

(2). The well-known theological problem of a omniscient or prescient God who, knowing in advance what each of us will do, necessarily deprives us of the power to choose freely.

(3). The more serious scientific threat to our free will, coming from determinist laws conjoined to initial conditions

These logical, theological and scientific arguments threaten in a similar way our free will, which typically requires as a necessary condition the possibility to choose between a set of different, real alternatives.

Bergson's approach to the problem and his defense of free will is targeted against the third conception of determinism and is based on the idea that, thanks to our direct intuition of the continuous flow of our inner experience, we are immediately aware of our freedom. Despite my 'reconstructive' approach, in order to summarize Bergson's philosophical attitude toward the issue of free will, it is necessary to put it in the context of his general philosophical outlook.

In order to go some way toward the achievement of this very ambitious aim in the very small space of a paper, I have decided to rely on a quotation from F.L. 
Pogson ${ }^{5}$ extracted from his introduction to Bergson's Time and Free Will essay, that he translated 1910. "If a man were to inquire of Nature the reason of her creative activity and if she were willing to give ear and answer, she would say - 'Ask me not, but understand in silence, even as I am silent and am not want to speak" (Pogson VIII, in: Bergson 2001, my emphasis). My choice is plausibly justified by the fact that Bergson himself agreed with the translator to use it as a motto summarizing his own philosophy up to 1910, a motto that is an epigraph taken from Plotinus.

My attempt at this point is to try to expand on the key words appearing in the succinct quotation above by discussing them in some more details.

\subsection{Nature}

First of all, according to Bergson, Nature (with a capital N) is active: as such, it is not to be conceived as a Cartesian clockwork composed by corpuscles impacting one another, or as Newtonian particles attracted by forces. Bergson's conception of nature is more similar to Leibniz's, even if the philosophical system constructed by the German philosopher is rather different. ${ }^{6}$

Despite his anti-cartesian conception of nature, Bergson inherited from Descartes a radical dualism between matter and mind, mirrored by his epistemic dualism between the two faculties of intellect and intuition. The intellect is a faculty that is essential for the effectiveness of our action in the material world because it is capable to separate and distinguish the objects in space and to fix in time the continuous, unified and temporal flux intuited by our consciousness (see also Russell 1914, 6). It must be kept in mind that, according to Bergson, it is this experienced continuity (of which we are immediately certain) that prevents an application of the concept of causality to our mental states.

5 In this paper I will follow Pogson's 1913 translation of the original text, as it has been checked by Bergson himself (Bergson 2001).

6 According to Leibniz, reality is composed of unextended, active centers of energy (monads), only part of which are conscious. Bergson's spiritualism has been much more influenced by the $19^{\text {th }}$ century advances in psychology and the neurocognitive sciences, but a deep analogy between the two philosophers is given by the fact that also our experience of duration, like any Leibnizian monad, only reflects part of realty, that according to Bergson consists of absolute duration. 


\subsection{Creativity and Novelty}

The other buzz word, creativity, cannot be discussed without making reference to the notion of élan vital as it is defined in the Creative Evolution, something that here, of course, cannot be done in full. In our context, suffice it to say that the creative, active power of Nature stands for the power to generate something new that did not exist before and that is unpredictable from the past. In his opinion, this kind of novelty is incompatible both with Darwin's "chance and necessity approach" and with a teleological account of living beings. In fact, Bergson's creative power does not just concern living beings, but penetrates the whole of $\mathrm{Na}$ ture and therefore pervades also inorganic matter.

With respect to this view, it is indispensable to recall the proximity of Bergson's notion of duration to Whitehead's concept of process, whose main philosophical outlook was greatly appreciated by the French philosopher, ${ }^{7}$ given that the former extended such a concept to all matter, animated and inanimate. A process for Whitehead is something that cannot be crystallized as a change of things in time but is the basis of the identification of the being of the world with its becoming. The moment of becoming is indeterminate, since it is only after the process has taken place that can we regard it as a fact and therefore as subject to causation. Clearly, the perception of an event that is happening in the present can be fully described only after the event has taken place, but according to Bergson it can be made sense of only when the whole constellation of memories that is related to it emerges to our mind, or only post factum so to speak.

Three main remarks must be pointed out at this stage, in particular vis à vis the role of the past in Bergon's notion of creativity.

(1) The first point involves the psychic experience of a growing past and its ontological correlate. Given his idea that each present experience $P$ occurring at a time $t_{1}$ is pregnant with a growing past, $P$ is different from any other experience, past or future. The reason is that $P$ also contains the immediate, continuously flowing memory of all past experiences: our past experiences affect the way we live the present ones. In addition, remembering the past, as Primo Levi also had it (1969), is not a passive but a creative act, given that the content of the present, unique recollection $R$ of a past event $E$ is constantly influenced by whatever has been experienced after the direct experience of $\mathrm{E}$ and before $R{ }^{8}$

7 For a comparison of Bergson's metaphysics with Whitehead's philosophy, I am greatly indebted to one of the two referees, whose suggestions have been extensively used in the following lines.

8 A contemporary explanation in scientific terms of this essential phenomenon is given in Edelman (1980). 
The same destiny occurs to $R$ after its occurrence, so that our memory of $E$ is always different. The key difference between spatial and temporal experience is well expressed by the following passage:

Our experience of duration is unlike the quantitative homogeneity presupposed by the concept of space: things in space can be counted because they are external one to the other in a homogenous medium. On the contrary, our immediate experience of time (duration) is heterogeneous because each immediately given data is always different and yet is unified by an act of 'unification of disparate content': 'several conscious states are organized into a whole, permeate one another, [and] gradually gain a richer content’ (Bergson 2001, 122).

This constantly changing interpenetration of different temporal experience makes time wholly different from the multiplicity of objects in space and is what Bergson calls duration; the richer content of our experience of time is due to the above-mentioned role of memory, extending more or less in the past (immediate, closer or more remote). Counting objects on the contrary, presupposes time (as in Kant) but the activity of counting is possible only because each counted object is external to any other.

On the contrary, we cannot "count" the different temporal experiences in succession: Bergson's "organization in the whole of several conscious states" points to the well-known fact that $a$ succession of experience is not an experience of succession. The latter is a synthetic act. In order to gain a deeper understanding of what Bergson calls "unification of disparate content" one can refer to contemporary phenomenological discussions about the extendedness of the experienced present, the so-called "Specious Present", a term coined by Clay (1882) and then further articulated by the American psychologist and philosopher William James (1890) and many others after him. Our experience of music is often used to illustrate conceptions that are similar to Bergson's holistic approach to temporal experience (see for example Husserl 1990): when we hear a succession of a few notes forming a melody, we unify in a single, simultaneous experience what is temporally successive (the single notes). Contemporary discussions ${ }^{9}$ about the psychology of our temporal experience are therefore highly indebted to Bergson's seminal intuitions.

Even though Bergson does not go so far as to imply that the psychic novelty of the contents of our mental acts depends on what we would call today a "Growing Block Model Of Reality”, I daresay that he would not be, at least prima facie, wholly unsympathetic with such a metaphysical underpinning of our subjective

9 For a review of the empirical literature on the nature of our present experience, see, among others, Dorato and Wittmann (2019). 
experience of accumulations of memories. The so-called "Growing Block View of Reality”, originally formulated by Broad (1923), claims that there is literally nothing after the present moment (the future so to speak is "empty"), while the present is the moment in which new elements of reality that did not previously exist become actual. What has become present remains forever part of reality, since it must be presupposed to explain the incessant creative power of Nature. ${ }^{10}$

There is an obvious reason to associate the Growing Block metaphysics to Bergson's view of time. In fact, it would explain our experience of an always richer temporal experience, given by the accumulation of memories with the constant change of future events becoming real in the present. The constant increase of our memories corresponds to, and can explained by, a continuous "accumulation" of real facts or events in the world. It is interesting to note that a metaphysical model according to which, as is typical our understanding of our life, each passing day is closer to the moment of our death, and more and more remote to the moment of our birth, would contradict Bergson's view, since in this "erosionist" model, the past would become less and less real. ${ }^{11}$

In his Introduction to metaphysics, these intuitions are expressed by Bergson with the metaphor of the two spools "with a tape running between them, one spool unwinding the tape, the other winding it up" (see Lawlor and Moulard 2020).

(2) The second remark anticipated at p. 68 is the fact that Bergson rejected any Darwinian explanation of the origin of new species: as such, his natural philosophy runs counter to what today (and to a lesser extent also at his times) is a very well-confirmed scientific theory. To the extent that a naturalistic metaphysics requires that metaphysical hypotheses should at least be logically consistent with the results of our best scientific theories, Bergson's metaphysical view should be rejected, based as it is on an anthropomorphic view of life, according to which "life, from its origin, it is the continuation of one and the same impetus, divided into divergent lines of evolution” (Bergson 1911, 61).

Interestingly, his major objection against Darwin's idea of natural selection is frequently voiced also today by contemporary creationists: it is impossible to explain the complexity and the teleological features of living beings by introducing what he calls a "mechanistic hypothesis". The mechanistic hypothesis that he is referring to corresponds to Darwin's natural selection acting on variations due to contingency and chance: "What likelihood is there that, by two entirely different

10 I owe the idea to explain Bergson's thesis of novelty with this metaphysical view to Simone Gozzano, with whom I discussed it at some length.

11 See Casati and Torrengo (2011); Norton (2015). 
series of accidents being added together, two entirely different evolutions will arrive at similar results?” (Bergson, 1911, 63-64, my emphasis). As in Duration and Simultaneity-vis à vis the twin paradox and the special theory of Relativity-also in this case his criticism to Darwinism is based on a serious misunderstanding, according to which "two divergent branches of evolution converge to the same point” (Bergson, 1911, 63-64).

This is not what happens in the evolution of species as it was described by Darwin and as we know it today: the divergence of traits does not imply convergence as Bergson has it, but rather more divergence. Supposing that Bergson had read Darwin's main book (he quotes from it), in his understanding of Darwinism he neglects completely the fact that natural selection, acting differentially on the constantly changing DNA of the various species, favor those that are capable of reproduction by giving birth to more descendants. In Bergson's instead, the creative evolution of life works against inert matter by promoting complexity.

In a word, according to Bergson, Darwin's mechanistic explanation is not sufficient to explain the origin of novelty in nature, which depends on a vital impetus (élan vital) that overcomes the resistance of inert matter, a hypothesis which to a contemporary reader remains completely unexplained.

However, according to Bergson, neither Darwinian mechanicism nor a mere teleological approach to evolution would ensure the kind of novelty that he is after, since also within the latter approach the whole (the telos) would already be given at the beginning, as in a foetus.

The doctrine of teleology, in its extreme form, as we find it in Leibniz for example, implies that things and beings merely realize a previously arranged program. However, according to Bergson, "if there is nothing unforeseen, no invention or creation in the universe, time is useless again. As in the mechanistic hypothesis, here again it is supposed that all is in advance. Finalism, thus understood is only inverted mechanism” (Bergson 1911, 45, my emphasis).

From this passage, it is clear that Bergson identified the "creative power" of nature producing novelties with the unforeseen or the contingent, which takes us to our third remark.

(3) The third way of understanding the notion of creativity comes from the opposition between determinism and indeterminism. In this third sense, which is the most important for the purpose of this paper, according to Bergson novelty requires the failure of determinism (see the sentence italicized above). Parentetically, Bergson had received an excellent mathematical education, and he was certainly aware of the locus classical of the definition of determinism given by Laplace in his 1820's Treatise on Probability: 
We ought to regard the present state of the universe as the effect of its antecedent state and as the cause of the state that is to follow. An intelligence knowing all the forces acting in nature at a given instant, as well as the momentary positions of all things in the universe, would be able to comprehend in one single formula the motions of the largest bodies as well as the lightest atoms in the world, provided that its intellect were sufficiently powerful to subject all data to analysis; to it nothing would be uncertain, the future as well as the past would be present to its eyes (quoted in Nagel 1961, 282-283). ${ }^{12}$

It is often but incorrectly alleged that determinism is incompatible with true novelty in the universe: in this case, we are told with a misleading metaphor that the whole temporal evolution of the world would be "contained" in the initial conditions. ${ }^{13}$ But note that this would be true only if determinism amounted to the epistemic notion of predictability as in Laplace's passage above endorsed also by Bergson (see note 12). But this is not the case, as deterministic chaos abundantly shows. Within chaotic phenomena, the evolution of a system is dictated by a deterministic equation, but its evolution soon becomes unpredictable, where the "soon" in question depends on the system one is considering. ${ }^{14}$ It is only if predictability implied a complete information about the initial state of the universe (an impossible ideal) that could we claim with some reason that (1) in deterministic models of the universe the present and the future are all (epistemically/informationally) "contained" in the past so that (2) no creative power or novelty can be attributed to nature.

In other words, unpredictability is not sufficient to defend free will, since also within the Growing Block-in which future events don't exist unrestricted$1 y^{15}$-we have both complete novelty and at the same time a deterministic though thoroughly unpredictable evolution of physical systems. On the other hand, the block view of the universe, which is closed to novelties regarded as coming into being, is compatible with indeterminism. Since my third interpretation of Bergson's view of the creative power of Nature is grounded in the text, we must conclude that one cannot defend the view that novelty is guaranteed by unpredictability. And yet, many followers of Bergson, after the quantum revolutions,

12 Here is Bergson's very similar reinstatement of Laplace's passage: “A superhuman intellect could calculate, for any moment of time, the position of any point of the system in space. And as there is nothing more in the form of the whole than the arrangement of its parts, the future forms of the system are theoretically visible in its present configuration” (Bergson 1911, 11).

13 As we have seen, mutatis mutandis for Bergson the same claim holds for a teleological account of life.

14 See Ruelle (1991).

15 See Mozersky (2011) for the meaning of unrestricted quantification; for instance, the current pandemic, in year 2018 was not existing and yet the universe could be in principle deterministic. 
argued incorrectly that the new Quantum Mechanics, allegedly introducing indeterminism in nature ${ }^{16}$, was a confirmation of Bergson's philosophy of nature.

One of the founding fathers of the theory, Louis De Broglie argued that "if Bergson could have studied quantum theory in detail ... he could doubtless have repeated, as in The Creative Mind, that 'time is this very Hesitation or it is nothing"' (De Broglie 1941, quoted in Canales 2015, 235). De Broglie clearly identifies the hesitation of the quantum system before measurement with the unreducible chance that the experimental apparatus reveals when the state of the system is not in a eigenstate of the observable. Keeping in mind that causal knowledge corresponds in the language of the first two decades of the last century to Kausalgesetz or determinism, Canales tells us that the (alleged) attacks on causal knowledge due to Quantum Mechanics was regarded as consonant to Bergsonism by authoritative journals of philosophy. There is even a conversation that has been reported according to which Bergson would have said "that which is funniest [drôle], is that physicists have come back to find liberty!” (Mondor 1957, 69).

The illegitimate and superficial identification of Heisenberg's principle of indeterminacy relations with a failure of causation (determinism) depends on the fact that the formulation of determinism needs at the same time a definite and simultaneous specification of position and momentum of a particle, a fact that in Quantum Mechanics cannot be achieved since position and momentum are conjugate variables and cannot be measured by the same apparatus at the same time. But this principle does not entail that the theory is indeterministic; in fact, widely discussed and exact deterministic formulations of Quantum Mechanics (like that offered by Bohmian mechanics) assume that the quantum probabilities are epistemic. ${ }^{17}$ Furthermore, from a more rigorous philosophical perspective, indeterminism, if regarded as imposing a branching structure to time-in which a unique past diverges into many possible futures, all compatible with the same past-cannot be regarded as a sufficient condition for a free choice in as in libertarian philosophical frameworks. Consequently, the role of chance in any human deliberation must be discussed less superficially: deciding what we ought to do by throwing a "quantum coin" cannot the paradigm of a rational choice. And for the compatibilists, indeterminism is not a solution to the problem of the freedom of the will: one needs additional arguments to reject

16 Caution is needed because alternative formulations of quantum theory, like Bohmian mechanics, are fully deterministic. See Goldstein (2017).

17 See Goldstein (2017). 
the compatibilist view, according to which our will is free when it is unconstrained, even if determined by previous desires.

In a word, if (a) the creating power of nature in Bergson's sense consists in the fact that its temporal evolution produces unpredictable elements and if (b) freedom consists in this unpredictability, this third sense of novelty is as implausible as the second, which engages a desperate fight against Darwin's explanation of the evolution of species. For this reason, a plausible interpretation of the creative power of nature is given, rather, by a metaphysics of a Growing Block, which might explain why Bergson identified novelty and freedom: each act of our consciousness is free because, even on determinism, it is different from the previous ones despite the similarity of the circumstances of choice, and reality can be regarded at least in part as brought about by our intentions and actions. I will now try to connect this conception of freedom to some key passages in the Essai sur les données immédiates de la conscience.

\section{Freedom in Time and Free Will}

In the third chapter of the book Time and Free Will Bergson analyses very carefully the problem of determinism, regarded both from the physical and the psychological perspective. In the physical realm, the principle of conservation of energy, acting on corpuscles subjects to the law of attraction and repulsion is assumed for the sake of the argument (Bergson 2001, 145). But Bergson decidedly questions its appropriateness for a psychological kind of determinism, since this thesis depends on the possibility of considering our psychical states as invariably correlated to physiological states.

Before discussing the positive side of his conception of free will, we must stress his opposition to the claim that the principle of the conservation of energy-which became central in physiochemical phenomena after the rapid development of thermal physics ${ }^{18}$-also applies to living beings. There might be a special kind of energy in the latter entities, due to the fact that, unlike what happens in inert matter, there cannot be a return to an initial state (except in intervals ot time exceeding the age of the universe, see also below). The inapplicability to living beings of the conservation of energy and therefore, on Bergson's view, to determinism as he sees it, ${ }^{19}$ depends on the irreversibility of the development of

18 Suffice to remind the reader of the two famous principles of thermodynamics stated by the German physicist Rudolf Klausius "The energy of the world remains constant. The entropy of the world tends to a maximum." (Klausius 1867, 400).

19 To a contemporary reader, this identification is dubious to say the least. 
living beings and in particular of conscious beings. Therefore, it depends on the different role played by time in inert matter and in our consciousness: "inert matter does not seem to perdure or to take any trace of past time” (Bergson 2011, 153). There is no real change in inertial matter, which seems to remain "in an eternal present" (Bergson 2011, 153), but in the case of conscious beings the duration or the extension of a past sensation in the present one implies a certain kind of gain: the past is always real for any state of consciousness, because any present sensation is affected by all of our past experience in the way sketched above.

The connection of free will with time should now be clear. In a nutshell, Bergson equates determinism with the principle of conservation of energy, and this principle in its turn with the (controversial) ${ }^{20}$ idea that physical time is fundamentally reversible (Albert 2010). Since there can never be a conscious state that repeats itself (each is pregnant with a different past), the principle of conservation of energy, and therefore determinism, according to Bergson, does not apply to conscious states. Before proceeding, it should be pointed out that Bergson's argument is rather weak. He is certainly on target when he considers the principle of conservation of energy to be one of the strongest arguments in favor of psychophysical parallelism or even (though he does not consider this possibility) of an identity theory of mind and brain. However, also in physics macroscopic time is irreversible, and the ubiquity of the growth of entropy must be explained in terms of time symmetric mechanical laws and initial conditions (presumably of the universe), in such a way that the entropy of a closed system never decreases. The return to the initial state, guaranteed by Poincarés recurrence theorem (Sklar 1993), requires a time that is longer than the age of the universe! Practically, there is no difference between physical and psychological time as far as irreversibility is concerned.

Furthermore, there are some physical processes, called non-Markovian, that do "keep trace" of the past, unlike Markovian process, which have no memory of the past since their probability depends only on the previous states. Bergson is right on target when he stresses that in living beings the past is much more important in determining their present and future states, but also the Earth, unlike an electron, keeps traces of its remote past, and the difference between conscious states and 'inert matter' in this respect could be regarded as one of degree.

Bergson continues his defense of free will by pointing out that there are two kinds of time - a theme that will return later in his debate with Einstein in $\mathrm{Du}$ ration and simultaneity (1965). One is the abstract time presupposed by mathe-

20 Some processes regarding muons in radioactive decay show a failure of temporal invariance (Horwich 1987). 
matics and physics, the other is the internal time of consciousness, which is pure duration (durée). ${ }^{21}$ One of the lasting contributions of Bergson's philosophy lies in his deep reflections on the conflict between these two notions of time: this question is still at the center of the contemporary philosophical debates on the nature of time. Bergson argues that, since many philosophers too often intermingle and confuse these two kinds of time, they come to think that also conscious states are subject to physical time. This is the main reason why they don't regard our actions as free: abstract time is presupposed by the study of inert matter, where determinism reigns with no limitations.

The fundamental argument that Bergson puts forth to defend our free will is his justified attack on associationist philosophy of mind, where the self is regarded (on the wake of Hume and Mill) as a mere collection of ideas and emotions, each of which is separated and external one to the other in a homogenous medium. In our internal life, on the contrary, Bergson correctly points out that conscious states "penetrate and melt one another, each tinged with the colouring of all the others" (Bergson 2001, 165). This implies that each of us loves and hates in different ways (Bergson 2001, 165), according to our different character, since each of us has had a different set of experiences, each of which reflects holistically all the others we had in the past like a monad reflects the universe. According to Bergson, the fact that our selves are singular and unrepeatable is another argument in favor of the fact that we possess a free will since, not only is the development of the self unpredictable and novel, but it is also characterized by duration, i.e., the permanence and fusion of all the relevant, remembered conscious states constituting a temporal experience. And once more, the link between time and free will emerges: abstract time goes together with associationism, which in its turn implies psychological determinism, while duration implies a duration in the present of all past conscious states of a person. In Bergson's view, a radically holistic conception of selfhood guarantees our free will since someone's personality is not given by the sum of her conscious state "but is present in each of them. And the outward manifestation of this inner state is what we call a free action, since the self alone will be the author of it, and since it expresses the whole of the self" (Bergson 2001, 165-66).

A reconstruction of this argument might go like this. If one acts upon a single detached desire or reason, the corresponding act will not express the whole personality of the doer, since on deterministic associationism, the self is frag-

21 It is ironic, even if not significant from a conceptual viewpoint to remark that in the Scholium to the Principia Mathematica Newton referred to absolute time, flowing equably, as duratio (duration)! 
mented into a detached series of conscious states, each of which is the deterministic cause of the next, and the personality results from the sum of causes and effects, each of which detached from the other. A deterministic action, in Bergson's view, would not express 'the whole of the self's past-and therefore one's entire personality-but, at any present moment of her life, only the content of the present experience, caused by immediately previous ones.

In contemporary terms, and stretching somewhat my hermeneutic/reconstructive approach, some such actions might even be regarded as the deeds of an addictive person, a wanton-who is incapable of postponing the satisfaction of her current desire (Frankfurt 1982)-and therefore as the actions of a person who discounts the future and does not act in virtue of an intention that integrates her whole life. The free actions are those in which the present state of mind takes into account the imagined future and the remembered past of the self, in such a way that an attitude that has been appropriately called temporal neutrality is not violated. ${ }^{22}$ For this reason, Bergson claims, if each conscious state is, thanks to its duration, inextricably entangled with all the others, the action will express the personality of the doer, her global, holistic self, and will therefore, in a very plausible sense, be free. In a word, according to Bergson freedom is self-expression, and therefore basically autonomy: the unconscious determination of our will should be compared to hypnosis, a phenomenon that later interested also Freud.

Actions done under hypnosis are paradigmatic examples of heteronomous determinations of our will, which, in Bergson's unfair rendering of determinism, exemplify a will guided by external forces. The rendering is unfair because also in compatibilist conceptions of free will, determinism is compatible with the claim that our will is free because we can do what we want, where the "we" refers to our will when it is not determined by external factors like hypnotic states, threats, and impediments of this kind. One could claim that also on compatibilism, determined motives of our actions are the expression of our personality, a claim that, pace Bergson, could be jeopardized only by the introduction of some form of chance or indeterminism separating the past from the future.

It is extremely important to stress the fact that Bergson correctly rejects the implausible idea that we enjoy an absolute form of freedom. In almost all actions of our life, we are guided by a sort of memory that today we would call procedural, the kind of automatic memory that is involved when we ride a bike or wash our hands. In these actions, there is no expression of the self and an association-

22 See Brink (2011). 
ist/deterministic description of the relevant action is appropriate: Bergson correctly likens them to "reflex acts" (Bergson 2001, 168).

In these actions, language plays a social role that, however, crystallizes our deepest self. In most of our waking hours, the means-to-end actions, in which what he calls the intellect plays a very important, indispensable practical role, the self does not emerge but remains at the surface. If I can interpret rather freely Bergson's point (but possibly not too unfaithfully to his explicit intentions) the rare but free actions are, instead, those in which "we form ourselves", to put it with Kane $(2005,130)$, who refers to these as self-forming actions. Similarly, Balaguer (2010) refers to "torn decisions" as those in which our free is particularly manifest. Since these actions fully reflect our past selves in a holistic way, they also shape the type of person that we will become in the future. In Bergson's language, a really free action expresses the whole enduring self, its past, its present and its future, in a word, its duration. It is appropriate to summarize what I just wrote with the following quotation, resembling Kane's conception of a free action. "It is at the great and solemn crisis, decisive of our reputation with others, and yet more with ourselves, that we choose in defiance of what is conventionally called a motive, and this absence of any tangible reason is the more striking the deeper our freedom goes" (Kane 2005, 130).

My brief synopsis of Bergson's understanding of the relation between time and free will would not be complete if I omitted to mention that the essential difference between time and space that he defends also serves to explain his criticism to the principle of alternative possibility (Van Inwagen 1986), on which almost every contemporary discussion on free will is based. Notably, in Bergson's opinion the branching time structure (one of the possible interpretations of his idea of novelty, see above) is inappropriate to defend or attack indeterminism or determinism. A branching, non-linear structure of time is a geometrical representation of a decision process that for Bergson essentially involves time and not space, because it is based on the becoming of the self and of the totality of reality.

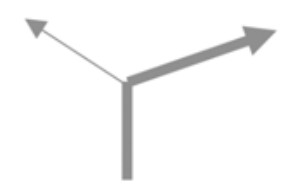

Fig. 1: At the bifurcation point, the free decision "brings" the history of the self to the "right".

The defender of libertarian conceptions argues that we could have done otherwise given the same past because the path (symbolizing the course of action we are about to take as in Fig. 1) "is not already taken, therefore it may take any direc- 
tion whatever" (Bergson 2001, 182) ${ }^{23}$ but then he continues "it is not possible to speak of a path till the action is performed. But then it will have been traced out" (Bergson 2001, 182). In fact, he continues, "before the path was traced out there was no direction either possible or impossible, for the very simple reason that it could not have been a question of a path" (Bergson 2001, 182). This reasoning is grounded on the presupposition that the principle of alternative possibility is based on a spatialization of time: in this case, the attempt to represent it with a fork (a path, see Fig. 1 above, where the bolded, thicker path is the one actually taken by the world, and the other path remains a possibility). But freedom is pure duration, becoming, so it cannot be crystallized by representing it with a spatial, symbolic graph. The idea here is that any symbolic representation involving space, the metaphor of the fork, is static, and then incapable of rendering the change in our conscious states in which becoming consists. Even "the moving now conception of time" (Skow 2015) would render only metaphorically the idea of the seamless change of the enduring self. On the contrary, the metaphysics of the Growing Block explains the accumulation of our memories and therefore, given Bergson's view of temporal experience the fact that to bring into being a previously non existing path and therefore a non existing reality.

One can accept his conception of selfhood and at the same time point out that his reasoning in the quoted passage is wrong. The evaluation of the future contingent certainly lies at the point of bifurcation, but even after a certain path has been taken, it makes sense to claim, counterfactually, that if the evolution of the world had been governed by indeterministic laws, the future could have been different without presupposing any change in the past state of the universe. In deterministic models, on the contrary, we could have done differently if the past had been different, so that the difference between deterministic/linear models and indeterministic/branching models remains even if the future is "empty".

\section{Bergson's Criticism of Language as an Instrument to Grasp Becoming}

In various passage of time and free will, Bergson points out that language, with its cataloguing function typical of juxtaposition in space of different things, has an extremely important practical role but is incapable of grasping the property that each enduring conscious state has to reflect throughout time the whole personality of a human being. We refer to love and hatred as if two different human

23 Here Bergson reproduces almost exactly the libertarian conception of free will. 
beings had the same feelings, which lead us to suppose that they are in the same mental state. Language must generalize via universals that, however, are not apt to grasp the uniqueness of an individual, which is a necessary and sufficient condition for her autonomy.

Pure duration escapes the limitation of language. This is the main reason why, in the opening quotation of the paper (Pogson's), silence is recommended as the best way to understand the creative power of nature, which manifests itself at the highest degree in our consciousness. It is intuition, our direct awareness of our inner states that leads us to decide one course of action rather than another. The intellect's only function is to calculate the consequences of our choice. However, this produces another drawback of Bergson's conception of a free choice. He says that looking back at an important decision, we have the impression that we acted without a reason (Bergson 2001, 170). He is led (if not forced) to defend this claim because he wants to leave room to our intuition and not just to the calculating, spatializing intellect. And, paradoxically, he claims that the more an action is without a reason, the more is free:

we wish to know why we have made up our mind, and we find that we have decided without any reason, and perhaps against every reason. But in certain cases this is best of reasons. For the action which has been performed does not then express some superficial idea, almost external to ourselves, distinct and easy to account for, but agrees with our most intimated feeling, thoughts and aspirations, with that conception of life which is equivalent to all our past experience (Bergson 2001, 170).

The obvious objection is why a conception of life that reflect all our past experiences should not be a conscious reason motivating us to choose one path rather than another. If the process that leads us to decide one path rather than another is hidden from us, it cannot be based on feelings, because typically we are aware of the feelings or emotions that move us to self-forming actions expressing our past. Furthermore, the opposition between feelings and reason is not supported by the contemporary neurophysiological research: ${ }^{24}$ without emotions or feelings no decision could be reached.

However, in order to be more charitable to Bergson's view, which should not be saddled with anachronistic considerations coming from contemporary discoveries but only with his own conceptual unclarities-this was after all the methodological assumption of this paper (see the introduction)-and in order to go some way toward justifying his position on the role of reasons in self-forming decisions of our life, we should consider that he intended reason in a very limited

24 See Damasio (1994) among others. 
sense, as a momentary cause of our action, which is called into play by the practical needs of our daily life. With this caveat in mind, we can agree with Bergson's claim that the really important decisions in our life are not due to momentary inclinations, but are expression of our whole selves regarded as enduring "entities". No duration of the selves, no self-forming decisions. However, it remains to be shown why this sort of decisions are free, in the sense that they are not an expression of some form of causal determinism encompassing a complex series of previous experiences. The fact that a temporally holistic conception of the self allows us to claim that the decision is a deep expression of the values of the individual person is not sufficient to claim that the motivation to follow one path rather than another is not fixed by previous events.

A final word on Pogson's reference to "our silence and Nature's silence" contained in the quotation above. Silence is necessary for the liberation of the self from the practical needs of our daily life based on our intellect that classifies objects on which we must act. Behind language there is space, the outer world, and therefore the crystallizing, abstract time of physics. But the true nature of the self is not expressible in words, because if this were possible, we would fragment our conscious states, thereby eliminating their duration in each of our actions. The elimination of this duration entails, as we have seen, a denial of our freedom. The cost to gain freedom is high: Bergson argues in favor of freedom with more or less plausible arguments that are however formulated in linguistic form: language is something we must get rid of in order to perceive the unity of the self with the creative, free power of Nature. So, in a way, this claim reminds us of the early Wittgenstein's approach to philosophy: in the case of Bergson, one must use language in order to show that language is necessary but not sufficient for a free action.

\section{References}

Albert, David Z. (2010), Time and Chance, Cambridge, MA.

Balaguer, Marc (2010), Free Will as an Open Scientific Problem, The Mit Press, Cambridge.

Bergson, Henri (1911), Creative Evolution, New York.

Bergson, Henri (1965), Duration and Simultaneity, New York.

Bergson, Henri (2001), Time and Free Will. Essay on the Immediate Given of Consciousness, New York.

Brink, David O. (2011), “Prospects for Temporal Neutrality”, in: Craig Callender (ed.) Oxford Handbook of Philosophy of Time, Oxford, 353-381.

Broad, Charlie D. (1923), Scientific Thought, Cambridge.

Canales, Jimena (2015) The physicist and the philosopher. Einstein, Bergson and the debate that changed our understanding of time, Princeton, New Jersey. 
Casati, Roberto/Torrengo, Giuliano (2011), “The not so incredible shrinking future”, in: Analysis 71 (2), 240-244.

Clay E.R. (pseudonim) (1882), The Alternative: A Study in Psychology, London.

De Broglie, Luis (1941), "Les conceptions de la physique contemporaine et les idées de Bergson sur le temps et sur le mouvement", in: Revue de Métaphysique et Morale 48 (4), 241-257.

Dorato, Mauro/Wittmann, Marc (2020), "The phenomenology and cognitive neuroscience of experienced temporality", in: Phenomenology and the Cognitive Sciences 19, 747-771.

Edelman, Gerald (1990), The Remembered Present: A Biological Theory of Consciousness, New York.

Fano, Vincenzo/Tassani, Isabella (2002), La riflessione filosofica sul tempo della fisica, Bologna.

Frankfurt, Harry G. (1982), “Freedom of the will and the concept of a person”, in: Gary Watson (ed.) Free Will, Oxford, 81-95.

Goldstein, Sheldon (2017), “Bohmian Mechanics”, in: The Stanford Encyclopedia https:// plato.stanford.edu/entries/qm-bohm/)

Horwich, Paul (1987), Asymmetries in Time, PrincetonNew Jersey.

Husserl, Edmund (1990), On the Phenomenology of the Consciousness of Internal Time (1893-1917), Dordrecht.

James, William (1890), The Principles of Psychology, 2 vol., New York.

Kane, Robert (1996), The Significance of Free Will, New York.

Kane, Robert (2005), A Contemporary Introduction to Free Will, Oxford.

Klausius, Rudolf (1867), Abhandlungen über die mechanische Wärmetheorie. Zweite Abtheilung, Braunschweig, xii $+354 \mathrm{~S}$.

Laplace, Pierre (1820), A Philosophical Essay on Probabilities - Preface, in: Ernest Nagel (1961), The structure of science, New York, 281-282.

Lawlor, Leonard/ Moulard, Leonard (2020), "Henri Bergson”, in: Edward N. Zalta (ed.), The Stanford Encyclopedia of Philosophy, https://plato.stanford.edu/archives/sum2020/en tries/bergson

Levi, Primo (1969), If this is a man, London.

Mondor, Henry (1957), Propos familiers de Paul Valéry, Paris.

Mozersky, Joshua (2011), "Presentism”, in: Craig Callender (ed.), The Oxford Handbook of Philosophy of Time, Oxford, 122-144.

Norton, John D. (2015), "The burning fuse model of unbecoming in time", in: Studies in History and Philosophy of Modern Physics 52, 103-105.

Ruelle, David (1991), Chance and Chaos, Princeton, New Jersey.

Russell, Bertrand (1914), The philosophy of BergsonCambridge.

Sklar, Lawrence (1993), Physics and Chance. Philosophical issues in the foundations of statistical mechanics, Cambridge.

Skow, Bradford (2015), Objective becoming, Oxford.

Van Inwagen, Peter (1983), An Essay on Free Will, Oxford. 